\title{
The Response of Durum Wheat to the Preceding Crop in a Mediterranean Environment
}

\author{
Laura Ercoli, ${ }^{1}$ Alessandro Masoni, ${ }^{2}$ Silvia Pampana, ${ }^{2}$ Marco Mariotti, ${ }^{3}$ and Iduna Arduini ${ }^{2}$ \\ ${ }^{1}$ Scuola Superiore Sant’Anna, Piazza Martiri della Libertà 33, 56127 Pisa, Italy \\ ${ }^{2}$ Department of Agriculture, Food and Environment, University of Pisa, Via del Borghetto 80, 56124 Pisa, Italy \\ ${ }^{3}$ Department of Veterinary Science, University of Pisa, Via delle Piagge 2, 56124 Pisa, Italy \\ Correspondence should be addressed to Laura Ercoli; ercoli@sssup.it
}

Received 8 July 2014; Accepted 8 September 2014; Published 21 October 2014

Academic Editor: Volker Mohler

Copyright (c) 2014 Laura Ercoli et al. This is an open access article distributed under the Creative Commons Attribution License, which permits unrestricted use, distribution, and reproduction in any medium, provided the original work is properly cited.

Crop sequence is an important management practice that may affect durum wheat (Triticum durum Desf.) production. Field research was conducted in 2007-2008 and 2008-2009 seasons in a rain-fed cold Mediterranean environment to examine the impact of the preceding crops alfalfa (Medicago sativa L.), maize (Zea mays L.), sunflower (Helianthus annuus L.), and bread wheat (Triticum aestivum L.) on yield and $\mathrm{N}$ uptake of four durum wheat varieties. The response of grain yield of durum wheat to the preceding crop was high in 2007-2008 and was absent in the 2008-2009 season, because of the heavy rainfall that negatively impacted establishment, vegetative growth, and grain yield of durum wheat due to waterlogging. In the first season, durum wheat grain yield was highest following alfalfa, and was $33 \%$ lower following wheat. The yield increase of durum wheat following alfalfa was mainly due to an increased number of spikes per unit area and number of kernels per spike, while the yield decrease following wheat was mainly due to a reduction of spike number per unit area. Variety growth habit and performance did not affect the response to preceding crop and varieties ranked in the order Levante $>$ Saragolla $=$ Svevo $>$ Normanno.

\section{Introduction}

Durum wheat (Triticum durum Desf.) is a traditional crop included in most dishes and food products consumed in the Mediterranean basin. Durum wheat producers are currently under pressure to maintain profitability against a background of environmental constraints, high fertiliser costs, and increasing quality demands of the pasta industry. Therefore, the development of cropping strategies that reduce input costs and increase the efficiency of fertilisers and simultaneously reduce the risks of nitrate leaching and denitrification is crucial [1].

A considerable volume of the literature addresses the effects of preceding crop on wheat. Kirkegaard et al. [2] carried out a survey of the literature on the effects of break crops, that is, crops interrupting the sequence of continuous wheat, and showed mean yield benefits of up to $20 \%$ or more, the magnitude of response depending on site, weather conditions, and other aspects of crop management. Overall, the inclusion of $\mathrm{N}_{2}$-fixing plants in crop rotations provided positive crop sequential enhancements to the yields of other crops compared to the nonleguminous crops [3]. Nix et al. [4] estimated the yield reduction in continuous wheat: the second successive wheat crop yields approximately $10 \%$ lower than the first, and the third wheat crop can yield $10-15 \%$ below the second. Lower yields for wheat planted after a high-residue crop with a high $\mathrm{C} / \mathrm{N}$ ratio compared with wheat planted after legumes have been attributed to greater immobilisation of $\mathrm{N}[5-7]$ or reduced disease control $[8,9]$. Autotoxicity may also result from the presence of phytotoxins produced by the preceding wheat crop building up in the soil with continuous culture over time $[3,10]$. Conversely, longterm studies in Mediterranean environments have produced evidence that, with adequate annual fertilisation and effective weed control, continuous wheat cropping may be used for many years without significant yield decline [11, 12].

Despite the many studies, a comprehensive picture of grain development under different environmental conditions has yet to emerge, particularly for profitable crop management. The objective of this study was to examine the impact 
of the preceding crops alfalfa, maize, sunflower, and wheat on the yield of durum wheat in a rain-fed cold Mediterranean environment. Four varieties were included in research over two seasons to test the hypothesis that variety growth habit and performance would affect the response to the preceding crop.

\section{Materials and Methods}

2.1. Experimental Conditions. Trials were carried out during two consecutive growing seasons (2007-2008 and 20082009) in Pisa, Italy $\left(43^{\circ} 40^{\prime} \mathrm{N}, 10^{\circ} 19^{\prime} \mathrm{E}, 1 \mathrm{~m}\right.$ a.s.l.). Seawater intrusion is not of concern in the area, as soil chemical analyses never indicated salinization in the $0-90 \mathrm{~cm}$ soil layer. The climate at the experimental site is characterised as cold humid Mediterranean with 120-year average of mean annual maximum and minimum daily air temperatures of 20.2 and $9.5^{\circ} \mathrm{C}$, respectively, and annual precipitation of $971 \mathrm{~mm}$, with $688 \mathrm{~mm}$ received during the period of durum wheat cultivation, which is from November to July [14]. The month normally receiving the greatest amount of rainfall is December (13\% of total).

Soil samples $(0-40 \mathrm{~cm}$ depth) were collected in November 2007 and December 2008 before wheat seeding. Samples were thoroughly mixed, air-dried, and ground and after sieving, material $<2 \mathrm{~mm}$ was analysed. Particle-size distribution was determined by the hydrometer method [15]. The $\mathrm{pH}$ was measured in a $1: 1$ soil- $\mathrm{H}_{2} \mathrm{O}$ suspension [16]. A modified wet-digestion Walkley-Black method [17] was used for the organic matter determination. Total soil $\mathrm{N}$ was measured by the modified Kjeldahl method [18]. Nitrate $\mathrm{N}$ was determined by the ion-selective electrode method [19], available $\mathrm{P}$ by the Olsen method, [20] and available K by the Dirks-Sheffer method [21]. Principal soil physical and chemical properties were $37 \%$ sand $(2 \mathrm{~mm}>\emptyset>0.05 \mathrm{~mm}) ; 39 \%$ silt $(0.05 \mathrm{~m}>$ $\emptyset>0.002 \mathrm{~mm}) ; 24 \%$ clay $(\emptyset<0.002 \mathrm{~mm}) ; 7.0 \mathrm{pH} ; 1.6 \%$ organic matter; $0.8 \mathrm{~g} \mathrm{~kg}^{-1}$ total nitrogen; $6.0 \mathrm{mg} \mathrm{kg}^{-1}$ available $\mathrm{P}$; and $149 \mathrm{mg} \mathrm{kg}^{-1}$ available $\mathrm{K}$. Soil texture was loam and soil type was Typic Xerofluvents according to the USDA soil taxonomy.

The durum wheat varieties Levante, Normanno, Saragolla, and Svevo (Breeder: Produttori Sementi Spa, Bologna, Italy) were established following alfalfa, maize, sunflower, and durum wheat on 25 November 2007 and 16 December 2008. Medium to high yielding varieties of durum wheat were chosen representing the high genotypic variability within commercial varieties in growth cycle length and grain quality. Levante, Normanno, Saragolla, and Svevo are new durum wheat varieties (released, resp., in 2002, 2002, 2004, and 1996) that are widely cultivated in Central Italy and differ in cycle length and grain quality. Levante and Normanno are medium maturing, Saragolla is early maturing, and Svevo is very early maturing. All have a high yellow index, and Levante and Svevo have a very high protein concentration, while Normanno is high and Saragolla medium-high. Finally, gluten quality is high in Normanno and Saragolla, medium in Levante, and low in Svevo.
Sixteen treatments, consisting of four preceding crops (alfalfa, Medicago sativa L., maize, Zea mays L., sunflower, Helianthus annuus L., and bread wheat, Triticum aestivum L.) and four varieties, were compared in both years. In Central Italy, wheat is typically rotated with maize and sunflower and to a lesser extent with alfalfa. Preceding crops were grown in adjacent fields and were rain-fed. The trial was laid out in a strip-plot design, with preceding crop as the main treatment with three replicates. Varieties were randomised within the main treatment. The area of each plot was $250 \mathrm{~m}^{2}$. The preceding crops wheat, sunflower, and maize were established and harvested in the years before the experiment, while alfalfa was established three years previously and terminated in the preceding year. Maize, sunflower, and wheat were grown for grain and alfalfa for hay. Following conventional cultural practices, alfalfa was cut four times per year. The biomass left in the field was approximately $500 \mathrm{~g} \mathrm{~m}^{-2}$ dry weight for alfalfa, $600 \mathrm{~g} \mathrm{~m}^{-2}$ for sunflower, $700 \mathrm{~g} \mathrm{~m}^{-2}$ for maize, and $400 \mathrm{~g} \mathrm{~m}^{-2}$ for wheat. Crops were cultivated following the technique normally applied in the area. Wheat was harvested in early July, maize was in mid-September, sunflower was in early August, and alfalfa was in early October.

Soil tillage before durum wheat sowing was performed by subsequent ploughing, disking (16 October 2007 and 5 October 2008), and harrowing (16 November 2007 and 15 December 2008). The previous crop residuals were incorporated into the soil by ploughing. Phosphorus and potassium were applied immediately before soil tillage as triple mineral phosphate $\left(\mathrm{Ca}\left(\mathrm{H}_{2} \mathrm{PO}_{4}\right)_{2} \cdot \mathrm{H}_{2} \mathrm{O}\right)$ and potassium sulphate $\left(\mathrm{K}_{2} \mathrm{SO}_{4}\right)$, at rates of $35 \mathrm{~kg} \mathrm{ha}^{-1} \mathrm{P}$ and $66 \mathrm{~kg} \mathrm{ha}^{-1} \mathrm{~K}$. Nitrogen was applied at $150 \mathrm{~kg} \mathrm{Nha}^{-1}$, split into three doses of 30 , 60 , and $60 \mathrm{~kg} \mathrm{Nha}^{-1}$, the first before soil harrowing as ammonium sulphate and the others as urea at pseudostem erection (24 March 2008 and 24 March 2009) and at first node detectable (7 April 2008 and 8 April 2009). Growth stages of pseudostem erection and first node detectable were individuated following the scale of Zadoks [13], corresponding, respectively, to GS30 and GS31. The fertilisers N, P, and K rates were calculated based on the balance approach. Durum wheat varieties were sown in rows $15 \mathrm{~cm}$ apart at the rate of 400 viable seeds $\mathrm{m}^{-2}$. Weed control was performed with a preemergence application of trifluralin.

2.2. Data Collection and Analyses. For all treatments, timings of the stage of 1st leaf emergence (GS10), 5th leaf unfolded (GS15), pseudostem erection (GS30), anthesis (GS60), and physiological ripening (GS90) were recorded, expressing in thermal time the duration of the periods between stages (Table 1). Thermal time was calculated following McMaster and Wilhelm [22], assuming $2^{\circ} \mathrm{C}$ as the base temperature [23]. At GS90 (22 June 2008 and 30 June 2009) wheat plants from a $1 \mathrm{~m}^{2}$ area were manually cut at ground level and were partitioned into stems (culms), leaves, nonseed portion of inflorescences (chaff), and caryopses (grain). For dry weight determination, samples from all plant parts were oven dried at $65^{\circ} \mathrm{C}$ up to constant weight. The number of spikes per unit area, mean kernel weight, number of spikelets per spike, and number of kernels per spike were measured at maturity. 
TABLE 1: Accumulated growing degree days (GDD) and rainfall during the whole wheat cycle and main growth periods. Growth stages are defined following Zadok's scale [13].

\begin{tabular}{lcccc}
\hline Period & \multicolumn{2}{c}{ GDD $\left({ }^{\circ} \mathrm{Cd}\right)$} & & Rainfall $(\mathrm{mm})$ \\
& $2007-2008$ & $2008-2009$ & $2007-2008$ & $2008-2009$ \\
\hline GS00-GS10* & 174.6 & 139.6 & 191.6 & 169.2 \\
GS10-GS15 & 405.8 & 381.5 & 38.6 & 206.4 \\
GS15-GS30 & 270.5 & 233.6 & 103.2 & 161.2 \\
GS30-GS60 & 751.4 & 793.3 & 140.6 & 69.2 \\
GS60-GS90 & 1039.7 & 1075.6 & 559.2 & 747.6 \\
Whole cycle & 2641.9 & 2622.5 & & \\
\hline
\end{tabular}

${ }^{*}$ GS00 seeding, GS10 emergence, GS15 5th leaf unfolded stage, GS30 pseudostem erection, GS60 anthesis, and GS90 physiological maturity.

Harvest index (HI) was calculated as (dry weight of grain/dry weight of aerial plant part $) \times 100$. Samples of each plant part were analysed for nitrogen concentration (modified Kjeldahl method, [18]); $\mathrm{N}$ contents were calculated by multiplying $\mathrm{N}$ concentration by dry weight. Since the effects of treatments were similar on leaves, culms, and chaff, data were combined together and hereafter referred to as the vegetative plant part. Spike fertility index (SFI) was calculated following the method of Abbate et al. [24] as the quotient between grain number $/ \mathrm{m}^{2}$ and spike chaff dry weight $/ \mathrm{m}^{2}$ at maturity. The durum wheat plots were evaluated for disease incidence and severity by visual assessment of symptoms of fungal infection.

2.3. Statistical Analysis. Results were treated with ANOVA. The main effects of year, preceding crop, variety, and their interactions were tested for all measured characters. The CoHort software package version 6.4 (CoHort software, Monterey, CA, USA) was used. Significantly different means were separated at the 0.05 probability level by the least significant difference test [25].

\section{Results}

3.1. Weather Conditions. Rainfall varied yearly over the 2year period: in 2007-2008 it was similar to the 120-year average in the area and was by $29 \%$ higher in 2008-2009 (Table 1). In 2007-2008, rainfall was well distributed through the wheat cycle and was more favourable for wheat growth and development. In 2008-2009, high rainfall occurred during autumn and low rainfall during spring. The variable rainfall patterns experienced during the study are typical for this wheat-producing area of the Mediterranean basin. Temperature was similar to the long-term average in both seasons, as the thermal time up to maturity was $2574^{\circ} \mathrm{C}$ in the long-term average versus $2642^{\circ} \mathrm{Cd}$ in $2007-2008$ and $2623^{\circ} \mathrm{Cd}$ in $2008-2009$ (Table 1). Accumulated growing degree days during wheat development phases were also alike in the two years.

3.2. Preplanting Nitrate Content in Soil. The soil $\mathrm{NO}_{3}-\mathrm{N}$ content before wheat sowing in both years was affected by the preceding crop. In the autumn of 2007 and 2008, more residual soil nitrate was available after alfalfa and values decreased in the following order: alfalfa, maize, sunflower,
TABLE 2: Effects of the preceding crop on preplant residual soil nitrate $\mathrm{N}(0-40 \mathrm{~cm}$ depth$)$.

\begin{tabular}{lcc}
\hline \multirow{2}{*}{ Preceding crop } & \multicolumn{2}{c}{ Residual soil nitrate $\mathrm{N}\left(\mathrm{mg} \mathrm{kg}^{-1}\right)$} \\
& 2007 & 2008 \\
\hline Alfalfa & $12.3^{\mathrm{a}}$ & $10.6^{\mathrm{a}}$ \\
Maize & $7.9^{\mathrm{b}}$ & $7.1^{\mathrm{b}}$ \\
Sunflower & $6.5^{\mathrm{b}}$ & $5.7^{\mathrm{b}}$ \\
Wheat & $4.2^{\mathrm{c}}$ & $3.3^{\mathrm{c}}$ \\
\hline
\end{tabular}

Within columns, numbers followed by the same letter are not significantly different at $P \leq 0.05$.

and wheat. Lower values were recorded in autumn 2008 after all crops (Table 2). Compared to the case of wheat as the preceding crop, soil $\mathrm{NO}_{3}-\mathrm{N}$ left after alfalfa was about threefold, resulting in an average of approximately $55 \mathrm{~kg} \mathrm{Nha}^{-1}$ in the $0-40 \mathrm{~cm}$ profile.

3.3. Grain Yield and Yield Components. Durum wheat grain yield and yield components were influenced by year, variety, and previous crop and by various interactions. The preceding crop differently affected grain yield according to the year of cultivation: in 2007-2008 grain yield was highest following alfalfa and, compared to this preceding crop, was 33\% lower following wheat. In 2008-2009 no difference in grain yield was detected among preceding crops (Table 3). In 2008-2009, wheat yields were low (less than $400 \mathrm{~g} \mathrm{~m}^{-2}$ ) due to high rainfall during the vegetative phase of plant development and low rainfall during the reproductive phase, leading to delayed emergence and prolonging the period during which plants are more sensitive to waterlogging. Moreover, poor crop establishment was associated with stunted growth due to high $\mathrm{N}$ leaching.

Differences in grain yield between years and preceding crops were due to variations in yield components. Mean kernel weight was $46 \%$ higher in 2007-2008 compared to 2008-2009 and was not affected by the preceding crop (Table 4). Conversely, the average number of kernels per spike in 2007-2008 compared to 2008-2009 was 38, 18, and $20 \%$ higher following alfalfa, maize, and sunflower, respectively, while wheat as preceding crop did not produce variation between years (Table 3). The number of spikes per unit area was affected by the preceding crop, with the lowest value 
TABLE 3: Grain yield, vegetative growth, and kernel number per spike. Year $\times$ preceding crop interaction.

\begin{tabular}{|c|c|c|c|c|}
\hline $\begin{array}{l}\text { Treatments } \\
\text { Year }\end{array}$ & Preceding crop & $\begin{array}{c}\text { Grain yield } \\
\left(\mathrm{g} \mathrm{m}^{-2}\right)\end{array}$ & $\begin{array}{l}\text { Vegetative growth } \\
\left(\mathrm{g} \mathrm{m}^{-2}\right)\end{array}$ & $\begin{array}{c}\text { Kernels per spike } \\
\left(n \text { spike }^{-1}\right)\end{array}$ \\
\hline \multirow{4}{*}{ 2007-2008 } & Alfalfa & $573.2^{\mathrm{a}}$ & $631.7^{\mathrm{a}}$ & $34.6^{\mathrm{a}}$ \\
\hline & Maize & $462.2^{\mathrm{b}}$ & $550.9^{\mathrm{abc}}$ & $28.9^{\mathrm{bc}}$ \\
\hline & Sunflower & $497.3^{\mathrm{b}}$ & $585.0^{\mathrm{ab}}$ & $29.6^{\mathrm{b}}$ \\
\hline & Wheat & $300.7^{\mathrm{c}}$ & $431.4^{\mathrm{cd}}$ & $23.4^{\mathrm{d}}$ \\
\hline \multirow{4}{*}{ 2008-2009 } & Alfalfa & $281.1^{c}$ & $364.8^{\mathrm{d}}$ & $25.0^{\mathrm{cd}}$ \\
\hline & Maize & $326.2^{c}$ & $472.3^{\mathrm{bcd}}$ & $24.5^{\mathrm{d}}$ \\
\hline & Sunflower & $294.3^{c}$ & $397.3^{\mathrm{d}}$ & $24.8^{\mathrm{d}}$ \\
\hline & Wheat & $276.4^{\mathrm{c}}$ & $401.7^{\mathrm{cd}}$ & $26.9^{\mathrm{bcd}}$ \\
\hline
\end{tabular}

Within columns, numbers followed by the same letter are not significantly different at $P \leq 0.05$.

TABLE 4: Mean values of spike number, mean kernel weight, spike fertility index, and spikelet number per spike as affected by year, preceding crop, and variety.

\begin{tabular}{|c|c|c|c|c|}
\hline Treatments & $\begin{array}{l}\text { Spike number } \\
\mathrm{n} \mathrm{m}^{-2}\end{array}$ & $\begin{array}{l}\text { Mean kernel weight } \\
\text { mg }\end{array}$ & $\begin{array}{l}\text { Spike fertility index } \\
\qquad \mathrm{ng}^{-1}\end{array}$ & $\begin{array}{c}\text { Spikelet number } \\
\text { n spike }\end{array}$ \\
\hline \multicolumn{5}{|l|}{ Year } \\
\hline $2007-2008$ & $312.4^{\mathrm{a}}$ & $52.7^{\mathrm{a}}$ & $57.3^{\mathrm{a}}$ & $17.8^{\mathrm{a}}$ \\
\hline 2008-2009 & $335.7^{\mathrm{b}}$ & $36.2^{\mathrm{b}}$ & $68.8^{\mathrm{b}}$ & $17.2^{\mathrm{a}}$ \\
\hline \multicolumn{5}{|l|}{ Preceding crop } \\
\hline Alfalfa & $318.7^{\mathrm{a}}$ & $43.7^{\mathrm{a}}$ & $70.7^{\mathrm{a}}$ & $17.7^{\mathrm{a}}$ \\
\hline Maize & $328.1^{\mathrm{a}}$ & $45.4^{\mathrm{a}}$ & $59.6^{\mathrm{b}}$ & $17.8^{\mathrm{a}}$ \\
\hline Sunflower & $325.5^{\mathrm{a}}$ & $44.2^{\mathrm{a}}$ & $59.0^{\mathrm{b}}$ & $18.0^{\mathrm{a}}$ \\
\hline Wheat & $263.1^{\mathrm{b}}$ & $44.5^{\mathrm{a}}$ & $52.1^{\mathrm{b}}$ & $16.4^{\mathrm{b}}$ \\
\hline \multicolumn{5}{|l|}{ Variety } \\
\hline Levante & $324.3^{\mathrm{a}}$ & $44.5^{\mathrm{a}}$ & $60.6^{\mathrm{a}}$ & $19.2^{\mathrm{a}}$ \\
\hline Normanno & $308.5^{\mathrm{a}}$ & $44.1^{\mathrm{a}}$ & $59.5^{\mathrm{a}}$ & $17.1^{\mathrm{b}}$ \\
\hline Saragolla & $279.1^{\mathrm{a}}$ & $43.1^{\mathrm{a}}$ & $58.2^{\mathrm{a}}$ & $18.1^{\mathrm{ab}}$ \\
\hline Svevo & $323.2^{\mathrm{a}}$ & $46.0^{\mathrm{a}}$ & $63.1^{\mathrm{a}}$ & $15.6^{\mathrm{c}}$ \\
\hline
\end{tabular}

${ }^{*}$ Spike fertility index: grain number $\mathrm{m}^{-2}$ /spike chaff dry weight $\mathrm{m}^{-2}$ at maturity.

Within treatments year, variety, and preceding crop, numbers followed by the same letter are not significantly different at $P \leq 0.05$.

for durum wheat following wheat compared to the other precessions (Table 4).

Grain yield of varieties was different in the two years (Table 5). In 2007-2008 production ranked in the order Levante $>$ Saragolla $=$ Svevo $>$ Normanno, while in 2008-2009 production of all varieties did not differ. Differences in grain yield between years and varieties were due to variations in the number of kernels per spike and mean kernel weight, as the number of spikes per unit area did not vary (Table 5). Mean kernel weight did not vary among varieties and was higher in 2007-2008 as previously discussed. The number of kernels per spike of Levante, Saragolla, and Svevo was, respectively, 25,28 , and $20 \%$ higher in 2007-2008 (Table 5). Grain yield was not affected by the interaction between variety and precession, as varieties responded similarly to the preceding crop (results not shown).

The response of the vegetative growth to the interaction year $\times$ preceding crop was similar to the same interaction in grain yield with maize and wheat as the preceding crops; vegetative growth was similar in the two years, while it was increased in $2007-2008$ by $73 \%$ with alfalfa preceding and by $47 \%$ with sunflower preceding (Table 3 ). Similar to grain, the vegetative plant part of Levante, Saragolla, and Svevo was higher in 2007-2008 (Table 5).

The harvest index was $46 \%$ in $2007-2008$ and $42 \%$ in 2008-2009 and was not modified by the preceding crop or variety (results not shown).

The number of spikelets per spike did not change in the two years but varied according to the variety and the preceding crop (Table 4). Varieties ranked in the following order: Levante $>$ Saragolla $=$ Normanno $>$ Svevo, and alfalfa, maize, and sunflower as preceding crops affected similarly spike size, while wheat as preceding crop reduced by $8 \%$ the number of spikelets per spike.

Comparing among the treatments, spike fertility index (SFI) differed between years and precessions. SFI was $20 \%$ higher in 2008 and alfalfa precession resulted in a $24 \%$ increase of SFI compared to other precessions (Table 4).

3.4. Nitrogen Uptake. Grain $\mathrm{N}$ concentration was not affected by the preceding crop but responded to the interaction year $\times$ variety, increasing by 20,12 , and $10 \%$ in 2008 -2009 compared 
TABLE 5: Grain yield, vegetative plant part, and kernel number per spike. Year $\times$ variety interaction.

\begin{tabular}{|c|c|c|c|c|}
\hline $\begin{array}{l}\text { Treatments } \\
\text { Year }\end{array}$ & Variety & $\begin{array}{c}\text { Grain yield } \\
\left(\mathrm{g} \mathrm{m}^{-2}\right)\end{array}$ & $\begin{array}{l}\text { Vegetative plant part } \\
\left(\mathrm{g} \mathrm{m}^{-2}\right)\end{array}$ & $\begin{array}{c}\text { Kernels per spike } \\
\quad\left(\mathrm{n} \text { spike }^{-1}\right)\end{array}$ \\
\hline \multirow{4}{*}{ 2007-2008 } & Levante & $570.0^{\mathrm{a}}$ & $619.4^{\mathrm{a}}$ & $32.9^{\mathrm{a}}$ \\
\hline & Normanno & $343.9^{\mathrm{c}}$ & $457.1^{\mathrm{bc}}$ & $23.7^{\mathrm{cd}}$ \\
\hline & Saragolla & $455.0^{\mathrm{b}}$ & $501.0^{\mathrm{b}}$ & $35.8^{\mathrm{a}}$ \\
\hline & Svevo & $464.5^{\mathrm{b}}$ & $621.5^{\mathrm{a}}$ & $26.2^{\mathrm{bc}}$ \\
\hline \multirow{4}{*}{ 2008-2009 } & Levante & $307.1^{\mathrm{cd}}$ & $445.4^{\mathrm{bcd}}$ & $26.4^{\mathrm{bc}}$ \\
\hline & Normanno & $305.2^{\mathrm{cd}}$ & $451.2^{\mathrm{bcd}}$ & $25.2^{\mathrm{bcd}}$ \\
\hline & Saragolla & $302.7^{\mathrm{cd}}$ & $375.6^{\mathrm{cd}}$ & $28.0^{\mathrm{b}}$ \\
\hline & Svevo & $263.1^{\mathrm{d}}$ & $363.8^{\mathrm{d}}$ & $21.7^{\mathrm{d}}$ \\
\hline
\end{tabular}

Within columns, numbers followed by the same letter are not significantly different at $P \leq 0.05$.

to 2007-2008, respectively, in Normanno, Saragolla, and Svevo (Figure 1(a)). Conversely, N concentration of grain of Levante did not change in the two years.

Nitrogen concentration in the vegetative plant part was not affected by the preceding crop and did not vary in the tested varieties but was mainly modified by the year of cultivation. Averaged over preceding crops and varieties, N concentration in the vegetative plant part was $6.6 \mathrm{~g} \mathrm{~kg}^{-1}$ in 2007-2008 and $4.0 \mathrm{~g} \mathrm{~kg}^{-1}$ in 2008-2009.

Following the patterns of dry weight and $\mathrm{N}$ concentration, $\mathrm{N}$ content of grain was affected by the interactions year $x$ precession and year $\times$ variety. The effect of the preceding crop on grain $\mathrm{N}$ content was different in the two years: in 2007-2008 grain N content following alfalfa was the highest, that following maize and sunflower was intermediate, and that following wheat was the lowest while in 2008-2009, grain $\mathrm{N}$ content was lowest and unaffected by the preceding crop (Figure 1(b)). In 2007-2008, grain N content in Levante, Saragolla, and Svevo was higher, while in 2008-2009 values in the four varieties were similar (Figure 1(c)). The highest $\mathrm{N}$ content in grain was recorded in Levante. Finally, grain $\mathrm{N}$ content in Normanno was lowest in both years, without any appreciable difference.

Nitrogen content of the vegetative plant part was not modified by the preceding crop or variety but was higher in 2008-2009 than in 2007-2008 (27.8 versus $23.5 \mathrm{~kg} \mathrm{ha}^{-1}$, data not shown).

\section{Discussion}

An ideal preceding crop for wheat should permit taking advantage of available water and nutrients while disrupting weed and disease cycles, resulting in decreased requirements for fertilisers, pesticides, and herbicides [26]. In our research, the response of durum wheat to the preceding crop was high in the favourable season (2007-2008) but was absent in the unfavourable one (2008-2009). In the most favourable season, durum wheat grain yield was highest following alfalfa and, compared to this preceding crop, was 33\% lower following wheat. Yield components are probably linked to increases in the yield potential of wheat following the tested preceding crops. Lower wheat yields in 2008-2009 were due to high rainfall during the vegetative phase of plant development and low rainfall during the reproductive phase, leading to delayed emergence and prolonging the period during which plants are most sensitive to waterlogging. Moreover, poor crop establishment was associated with stunted growth due to high $\mathrm{N}$ leaching.

The yield increase of durum wheat following alfalfa was mainly due to an increased number of spikes per unit area and number of kernels per spike, while the yield decrease following wheat was mainly due to a reduction of the number of spikes.

Nitrogen availability during both early and late crop development is a possible cause for the differences in growth and yield of durum wheat following the tested preceding crops. Differential $\mathrm{N}$ availability results from the balance between mineralization and immobilization of $\mathrm{N}$ in soil organic matter. The amount of released or immobilized $\mathrm{N}$ depends on the biomass and the $\mathrm{C} / \mathrm{N}$ ratio of residues left in the field by the preceding crop. We did not determine the $\mathrm{C} / \mathrm{N}$ ratio of residues but, according to [2], net $\mathrm{N}$ mineralization is expected from alfalfa residues, because of a $\mathrm{C} / \mathrm{N}$ ratio lower than 30; while net $\mathrm{N}$ immobilization is favored from maize, sunflower, and wheat residues, due to a $\mathrm{C} / \mathrm{N}$ ratio greater than 40. More residual soil nitrate $\mathrm{N}$ was available before durum wheat planting following alfalfa [2]. Observation of increased soil nitrate $\mathrm{N}$ levels following alfalfa, likely due to the mineralization of $\mathrm{N}$ in legume organic matter residues [27], confirms previous findings that net soil $\mathrm{N}$ mineralisation following alfalfa was 30 to $40 \%$ greater than that following maize or soybean [28]. Results of Gaiser et al. [29] suggest that alfalfa as the preceding crop supports deeper rooting and higher rooting density of following spring wheat, enhancing access to water and nutrients in deeper soil layers.

The assumption of an effect of late $\mathrm{N}$ availability is supported by the response of the spike fertility index, which was increased in durum wheat following alfalfa compared to the other precessions. The SFI is a complex trait that includes spike structure, that is, the assimilate partitioning inside the spike; development and survival of florets; and grain set. These processes follow a general pattern that is genetically predetermined but whose speed can be modified by environmental conditions, such as $\mathrm{N}$ fertilisation [30,31]. This experiment showed that durum wheat following alfalfa, while initiating a relatively similar number of spikelets to that 


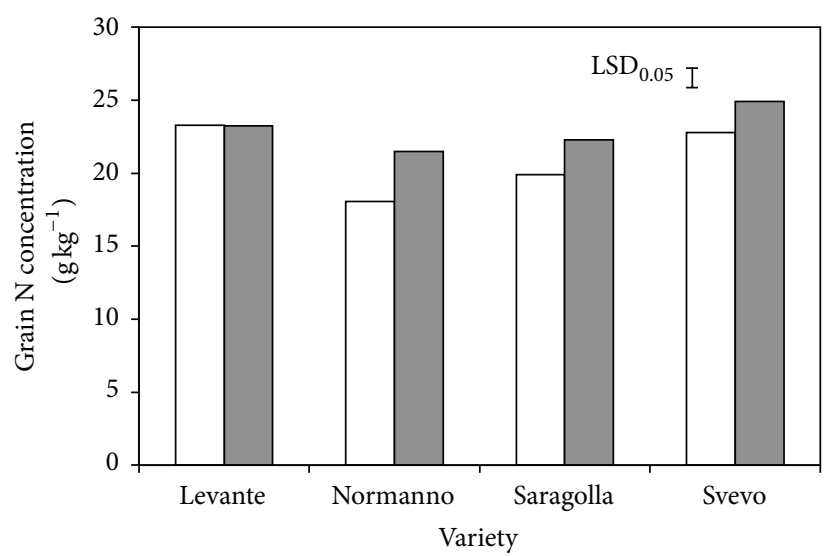

(a)

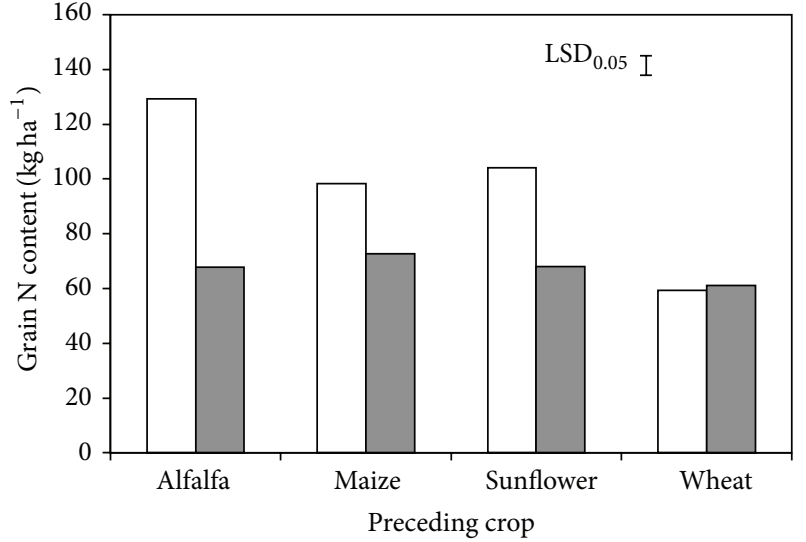

(b)

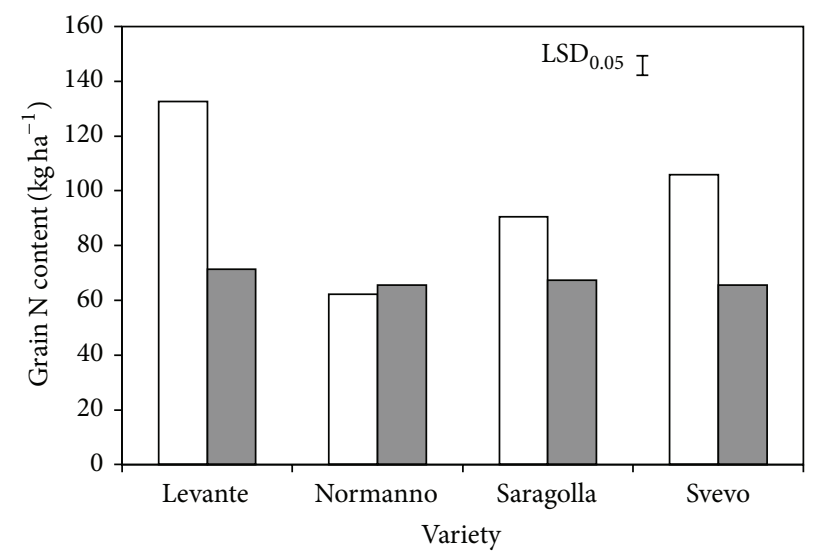

2007-2008

2008-2009

(c)

FIGURE 1: Grain N concentration as affected by variety (a) and grain N content as affected by preceding crop (b) and variety (c) mean effects. Bars indicate Fisher's LSD test at $P \leq 0.05$.

of durum wheat after other crops, set more grains per spike. Thus it is likely that the higher $\mathrm{N}$ availability in soil owing to the release of $\mathrm{N}$ from the mineralisation of legume residues allows higher floret survival at anthesis.

A possible explanation for differences due to preceding crops is also the toxic effect of allelochemicals released by wheat residues, affecting crop establishment $[9,10,32]$, which were not measured in the present study. It could be argued also that the durum wheat plants following wheat might take up $\mathrm{N}$ at lower rates because of a smaller root system, presumably due to the toxic effect of allelochemicals. Moreover, allelochemicals may also have an indirect effect on plant growth by affecting potentially beneficial rhizosphere microorganisms, for example, by inhibiting mycorrhizal formation or microorganisms involved in nutrient cycling [33].

Weed development was low and no evidence of disease was documented during the wheat growth and no relation was found with preceding crops. In particular, Fusarium sp. infection, representing one of the most harmful diseases in our environment, did not occur following either host crops like maize or wheat or nonhost crops like alfalfa or sunflower
[34]. Probably, climatic conditions during grain filling in both years were not favorable for infection, as Fusarium sp. is favoured by rainy and humid weather during grain filling [35].

Genotypic effects were mainly observed for grain yield and grain number, but variety growth habit and performance did not affect the response to preceding crop, in that no change in the rank order of varieties was observed. The rank order of the varieties for grain yield was also not related to cycle length or duration of grain filling but was due to increased number of grains per unit area.

\section{Conclusions}

Response of durum wheat varieties to preceding crop varied with prevailing weather conditions in the growing season. Overall, grain yield was $70 \%$ higher in the drier year. The durum wheat varieties in this study had similar reactions to the preceding crops. Wheat yields were influenced by previous crop. Preceding wheat exhibited the lowest yield, but 
this was not a factor of pests and disease incidence. Likewise, averaged over seasons and varieties, grain yield was increased by $48 \%$ when the preceding crop was alfalfa compared to wheat as preceding crop. This may be a favourable sequence for producers. This residual effect over years should be considered when formulating fertiliser requirements. Therefore, a better insight into the factors affecting the dynamics of immobilisation and remineralisation of fertiliser $\mathrm{N}$ is needed.

\section{Conflict of Interests}

The authors declare that there is no conflict of interests regarding the publication of this paper.

\section{References}

[1] D. L. Tanaka, J. M. Krupinsky, M. A. Liebig et al., "Dynamic cropping systems: an adaptable approach to crop production in the Great Plains," Agronomy Journal, vol. 94, no. 5, pp. 957-961, 2002.

[2] J. Kirkegaard, O. Christen, J. Krupinsky, and D. Layzell, "Break crop benefits in temperate wheat production," Field Crops Research, vol. 107, no. 3, pp. 185-195, 2008.

[3] J. M. Krupinsky, D. L. Tanaka, S. D. Merrill, M. A. Liebig, and J. D. Hanson, "Crop sequence effects of 10 crops in the northern Great Plains," Agricultural Systems, vol. 88, no. 2-3, pp. 227-254, 2006.

[4] J. Nix, P. Hill, and A. Edwards, Farm Management Pocketbook, The Andersons Centre, London, UK, 36th edition, 2006.

[5] W. L. Hargrove, J. T. Touchton, and J. W. Johnson, "Previous crop influence on fertilizer nitrogen requirements for doublecropped wheat," Agronomy Journal, vol. 77, pp. 855-859, 1983.

[6] S. J. Smith and A. N. Sharpley, "Nitrogen availability from surface applied and soil-incorporated crop residues," Agronomy Journal, vol. 85, pp. 776-778, 1993.

[7] S. A. Staggenborg, D. A. Whitney, D. L. Fjell, and J. P. Shroyer, "Seeding and nitrogen rates required to optimize winter wheat yields following grain sorghum and soybean," Agronomy Journal, vol. 95, no. 2, pp. 253-259, 2003.

[8] O. Christen, K. Sieling, and H. Hanus, "The effect of different preceding crops on the development, growth and yield of winter wheat," European Journal of Agronomy, vol. 1, no. 1, pp. 21-28, 1992.

[9] K. Sieling, C. Stahl, C. Winkelmann, and O. Christen, "Growth and yield of winter wheat in the first 3 years of a monoculture under varying $\mathrm{N}$ fertilization in NW Germany," European Journal of Agronomy, vol. 22, no. 1, pp. 71-84, 2005.

[10] H. Wu, J. Pratley, D. Lemerle, and T. Haig, "Allelopathy in wheat (Triticum aestivum)," Annals of Applied Biology, vol. 139, no. 1, pp. 1-9, 2001.

[11] A. S. Lithourgidis, C. A. Damalas, and A. A. Gagianas, "Longterm yield patterns for continuous winter wheat cropping in northern Greece," European Journal of Agronomy, vol. 25, no. 3, pp. 208-214, 2006.

[12] B. Procházková, J. Hrubý, J. Dovrtěl, and O. Dostál, "Effects of different organic amendment on winter wheat yields under long-term continuous cropping," Plant, Soil and Environment, vol. 49 , no. 10, pp. 433-438, 2003.

[13] J. C. Zadoks, T. T. Chang, and C. F. Konzak, "A decimal code for the growth stages of cereals," Weed Research, vol. 14, pp. 415-421, 1974.
[14] C. Moonen, A. Masoni, L. Ercoli, M. Mariotti, and E. Bonari, "Long-term changes in rainfall and temperature in Pisa, Italy," Agricoltura Mediterranea, vol. 131, pp. 11-22, 2001.

[15] G. W. Gee and J. W. Bauder, "Particle-size analysis," in Methods of Soil Analysis. Part 1. Physical and Mineralogical Methods, A. Klute, Ed., vol. 9 of Agronomy Monograph, pp. 383-411, American Society of Agronomy, Madison, Wis, USA, 2nd edition, 1986.

[16] E. O. McLean, "Soil pH and lime requirement," in Methods of Soil Analysis Part 2: Chemical and Microbiological Properties, Agronomy Monograph, A. L. Page, R. H. Miller, and D. R. Keeney, Eds., vol. 9, pp. 199-224, American Society of Agronomy, Madison, Wis, USA, 2nd edition, 1982.

[17] D. W. Nelson and L. E. Sommers, "Total carbon, organic carbon and organic matter," in Methods of Soil Analysis, Part 2, Chemical and Microbiological Properties, Agronomy Monograph, A. L. Page, R. H. Miller, and D. R. Keeney, Eds., vol. 9, pp. 539579, American Society of Agronomy, Madison, Wis, USA, 2nd edition, 1982.

[18] J. M. Bremner and C. S. Mulvaney, "Nitrogen-total," in Methods of Soil Analysis, Part 2, Chemical and Microbiological Properties, A. L. Page, R. H. Miller, and D. R. Keeney, Eds., vol. 9 of Agronomy Monograph, pp. 595-624, American Society of Agronomy, Madison, Wis, USA, 2nd edition, 1982.

[19] D. R. Keeney and D. W. Nelson, "Nitrogen in organic forms," in Methods of Soil Analysis. Part 2. Chemical and Microbiological Properties, A. L. Page, R. H. Miller, and D. R. Keeney, Eds., vol. 9 of Agronomy Monograph, pp. 643-698, American Society of Agronomy, Madison, Wis, USA, 2nd edition, 1982.

[20] S. R. Olsen and L. E. Sommers, "Phosphorus", in Methods of Soil Analysis, Part 2: Chemical and Microbiological Properties, A. L. Page, R. H. Miller, and D. R. Keeney, Eds., vol. 9, pp. 403430, American Society of Agronomy, Madison, Wis, USA, 2nd edition, 1982.

[21] G. W. Thomas, "Exchangeable cations," in Methods of Soil Analysis, Part 2, Chemical and Microbiological Properties, Agronomy Monograph, A. L. Page, R. H. Miller, and D. R. Keeney, Eds., vol. 9, pp. 159-165, American Society of Agronomy, Madison, Wis, USA, 2nd edition, 1982.

[22] G. S. McMaster and W. W. Wilhelm, "Growing degree-days: one equation, two interpretations," Agricultural and Forest Meteorology, vol. 87, no. 4, pp. 291-300, 1997.

[23] J. R. Porter and M. Gawith, "Temperatures and the growth and development of wheat: a review," European Journal of Agronomy, vol. 10, no. 1, pp. 23-36, 1999.

[24] P. E. Abbate, A. C. Pontaroli, L. Lázaro, and F. Gutheim, "A method of screening for spike fertility in wheat," Journal of Agricultural Science, vol. 151, no. 3, pp. 322-330, 2013.

[25] R. G. D. Steel, J. H. Torrie, and D. A. Dickey, Principles and Procedures of Statistics: A Biometrical Approach, McGraw-Hill, New York, NY, USA, 1997.

[26] D. L. Karlen, G. E. Varvel, D. G. Bullock, and R. M. Cruse, “Crop rotations for the 21st century," Advances in Agronomy, vol. 53, pp. $1-45,1994$.

[27] J. O. Siqueira, M. G. Nair, R. Hammerschmidt, and G. R. Safir, "Significance of phenolic compounds in plant-soil-microbial systems," Critical Review in Plant Sciences, vol. 10, pp. 63-121, 1991.

[28] A. J. Bennett, G. D. Bending, D. Chandler, S. Hilton, and P. Mills, "Meeting the demand for crop production: the challenge of yield decline in crops grown in short rotations," Biological Reviews, vol. 87, no. 1, pp. 52-71, 2012. 
[29] T. Gaiser, U. Perkons, P. M. Küpper et al., "Evidence of improved water uptake from subsoil by spring wheat following lucerne in a temperate humid climate," Field Crops Research, vol. 126, pp. 56-62, 2012.

[30] M. M. Acreche, G. Briceño-Félix, J. A. M. Sánchez, and G. A. Slafer, "Physiological bases of genetic gains in Mediterranean bread wheat yield in Spain," European Journal of Agronomy, vol. 28, no. 3, pp. 162-170, 2008.

[31] G. A. Slafer and F. H. Andrade, "Physiological attributes related to the generation of grain yield in bread wheat cultivars released at different eras," Field Crops Research, vol. 31, no. 3-4, pp. 351367, 1993.

[32] J. F. Power, J. W. Doran, and W. W. Wilhelm, "Uptake of nitrogen from soil, fertilizer, and crop residues by no- till corn and soybean.," Soil Science Society of America Journal, vol. 50, no. 1, pp. 137-142, 1986.

[33] L. Carpenter-Boggs, J. L. Pikul Jr., M. F. Vigil, and W. E. Riedell, "Soil nitrogen mineralization influenced by crop rotation and nitrogen fertilization," Soil Science Society of America Journal, vol. 64, no. 6, pp. 2038-2045, 2000.

[34] K. Klem, M. Váňová, J. Hajšlová, K. Lancová, and M. Sehnalová, "A neural network model for prediction of deoxynivalenol content in wheat grain based on weather data and preceding crop," Plant, Soil and Environment, vol. 53, no. 10, pp. 421-429, 2007.

[35] A. W. Schaafsma, D. C. Hooker, and J. D. Miller, "Progress and limitations with respect to pre-harvest forecasting of Fusarium toxins in grains," Phytopathology, vol. 95, p. 123, 2005. 


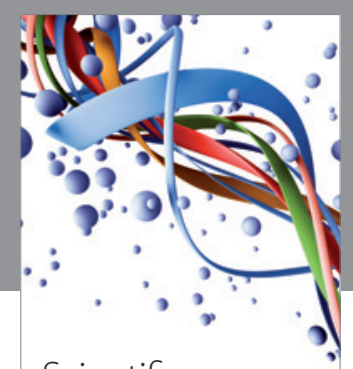

Scientifica
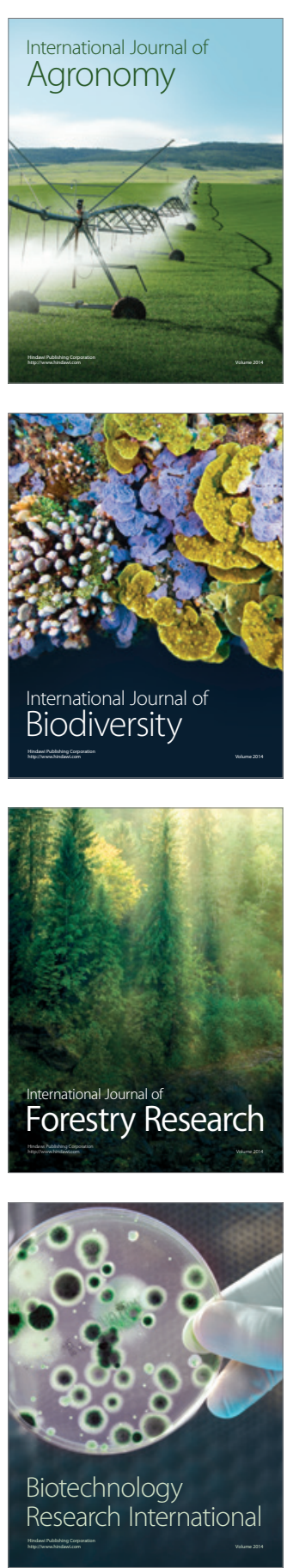
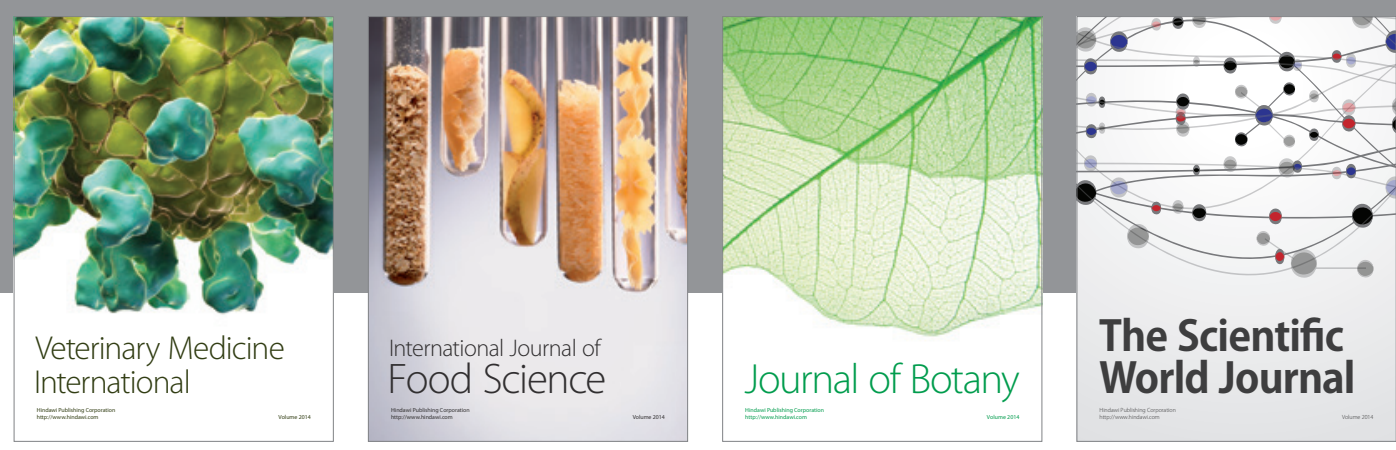

The Scientific World Journal
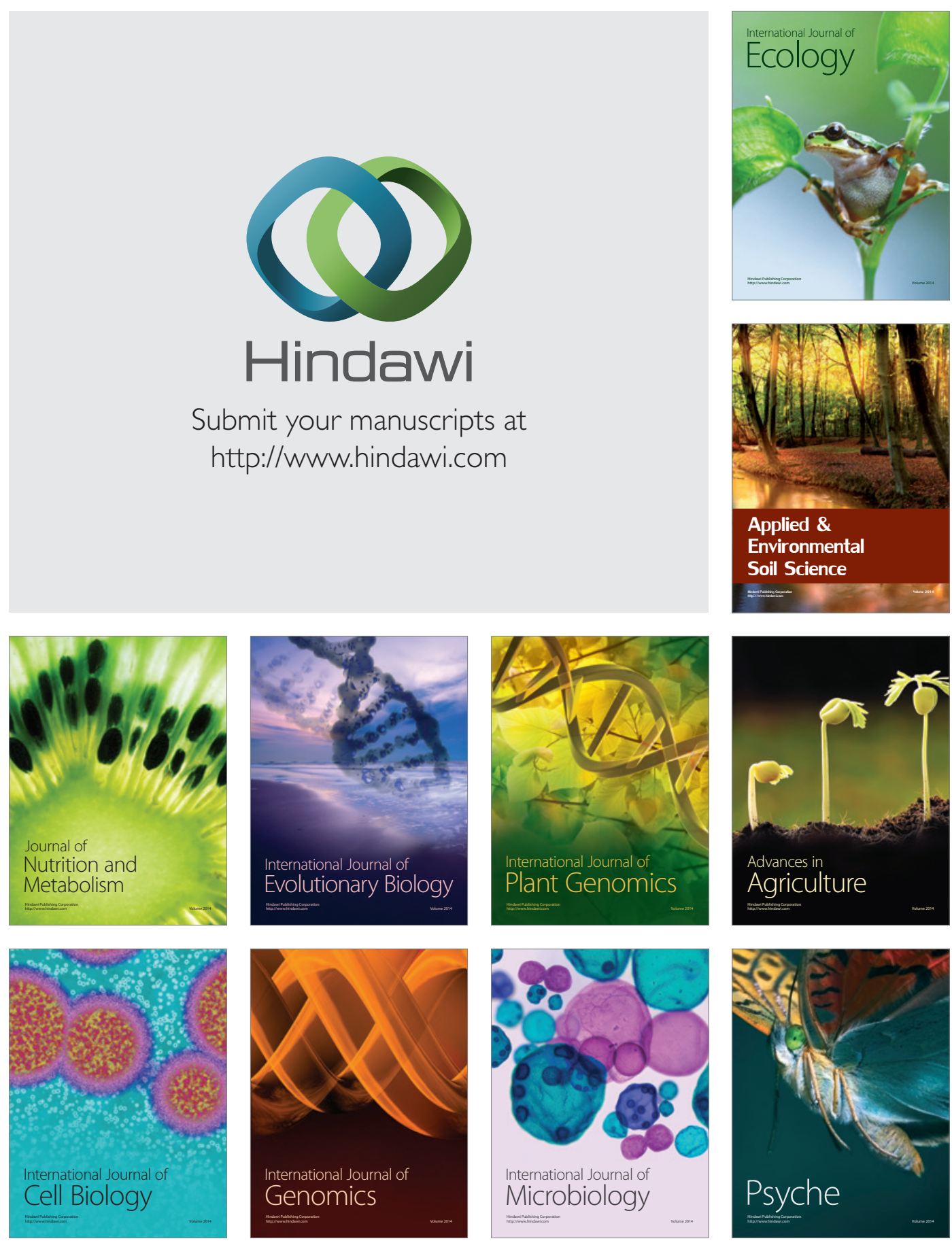